\title{
Non-invasive assessment of prosthetic mitral paravalvular and intravalvular regurgitation ${ }^{1}$
}

\author{
James T. Willerson, John A. Kastor ${ }^{2}$, Robert E. Dinsmore, Eldred Mundth, \\ Mortimer J. Buckley, W. Gerald Austen, and Charles A. Sanders \\ with the technical assistance of Harriet Walker \\ - From the Departments of Medicine (Cardiac Unit), Radiology, and \\ Surgery, Massachusetts General Hospital, and the Departments of Medicine, \\ Radiology, and Surgery, Harvard Medical School, Massachusetts, U.S.A.
}

The ability of certain non-invasive recording techniques to diagnose mitral paravalvular regurgitation and intravalvular regurgitation has been assessed. The data obtained from the 30 patients studied suggest that while the recognition of severe mitral paravalvular regurgitation is usually possible using phonocardiography and carotid arterial pressure recordings, mild cases may be difficult to diagnose. The most useful non-invasive measurement in this study was a reduced aortic closure to mitral valve opening interval (A2-OCMV) which occurred in association with - severe regurgitation in 3 of 4 patients (A2-OCMV $<0.08$ second). With milder degrees considerable overlap with patients with normally functioning mitral prostheses was present (2/3 with A2-OCMV $\overline{ } 0.08$ second). A conspicuously reduced left ventricular ejection time (LVET) was seen in some patients but there was overlap with patients with normally functioning prostheses ( $\triangle L V E T>70$ msec in 5/II with mitral paravalvular regurgitation and in 3/I5 with normally functioning mitral prostheses). Reduced opening clicks were found in association with but were not specific for mitral paravalvular regurgitation or tissue ingrowth into the prosthesis and intravalvular regurgitation. The presence or absence of systolic murmurs was misleading, and in the patients studied an unimpressive or absent apical systolic murmur in the presence of mitral paravalvular regurgitation suggested that it was severe.

Failure to improve clinically after mitral valve replacement is usually due to regurgitation through a paravalvular leak, to other uncorrected valvular lesions, to pulmonary embolic disease, or to myocardial disease. The distinction between these various possibilities on clinical grounds is often difficult. Furthermore, cardiac catheterization in these seriously ill patients carries a risk. There is evidence that non-invasive techniques may be useful in detecting mitral paravalvular regurgitation (Leachman and Cokkinos, 1969; Hultgren and Hubis, 1965). The purpose of this paper is to report the results of certain non-invasive

Received 20 July, 197I.

1 Supported in part by USPHS Grants. Presented in part at the Laennec Cardiovascular Sound Society at the American Heart Association meetings, November 1970.

2 Present address: Medical Intensive Care Unit, Hospital of the University of Pennsylvania, and University of Pennsylvania School of Medicine, Philadelphia, Pennsylvania, U.S.A. studies done on 30 patients after mitral valve replacement and to point out certain clues that may aid in the recognition of mitral paravalvular and intravalvular regurgitation.

\section{Methods and clinical data}

A total of 30 patients was studied after mitral valve replacement at intervals ranging from 7 days to 6 years after operation (mean 291 days) between the years 1967 to 1970 . The patients studied were divided into 3 groups as follows.

Group I This group consisted of II patients (5 men and 6 women) with either mitral paravalvular or intravalvular regurgitation. Nine had StarrEdwards mitral prostheses; one had a Kay Shiley, and one a Beall valve (Table I). Three also had aortic Starr-Edwards prostheses. All were on digitalis preparations, low sodium diets, and diuretics. None of them had systemic hypertension. Eight were in atrial fibrillation, 2 were in sinus rhythm, and one was being ventricularly paced at the time of study. Mean heart rate was 80 beats/min. Ten had mitral paravalvular and one (Case ro) had 
TABLE I Patients with paravalvular leaks

\begin{tabular}{|c|c|c|c|c|c|}
\hline Case No. & $\begin{array}{l}\text { Age and } \\
\text { sex }\end{array}$ & $\begin{array}{l}\text { Aetiology of original mitral } \\
\text { valve disease }\end{array}$ & Calcified valve & Valve & $\begin{array}{l}\text { Time leak } \\
\text { suspected }\end{array}$ \\
\hline $\mathbf{I}$ & $47 M$ & $\begin{array}{l}\text { Ruptured chordae tendineae } \\
\text { (myxomatous degeneration) }\end{array}$ & None & Starr-Edwards & $24 \mathrm{hr}$ \\
\hline 2 & 6I F & Rheumatic & Heavily calcified & Kay Shiley & $7 \mathrm{dy}$ \\
\hline 3 & $50 \mathrm{~F}$ & Rheumatic & Heavily calcified & Starr-Edwards & I yr \\
\hline 4 & $63 \mathrm{~F}$ & Rheumatic & $\begin{array}{l}\text { Calcium present but exact } \\
\text { amount unknown }\end{array}$ & Starr-Edwards & 4 wk \\
\hline 5 & $54 \mathrm{~F}$ & Rheumatic & Heavily calcified & Starr-Edwards & I yr \\
\hline 6 & $57 \mathrm{M}$ & Rheumatic & Heavily calcified & Starr-Edwards & I yr \\
\hline 7 & $58 \mathrm{M}$ & Rheumatic & None & Beall & $5 \mathrm{dy}$ \\
\hline 8 & $45 \mathrm{M}$ & Rheumatic & Heavily calcified & Starr-Edwards & Io wk \\
\hline 9 & $38 \mathrm{M}$ & Rheumatic & Heavily calcified & Starr-Edwards & $6 \mathrm{mth}$ \\
\hline 10 & $59 \mathrm{~F}$ & Rheumatic & Heavily calcified & Starr-Edwards & $3 \frac{1}{2}$ yr \\
\hline II & $53 \mathrm{M}$ & Rheumatic & Heavily calcified & Starr-Edwards & I yr \\
\hline
\end{tabular}

* Time leak suspected, when systolic murmur suggestive of paravalvular leak was noted or clinical deterioration suggested paravalvular leak after mitral valve replacement.

intravalvular regurgitation, the latter being due to tissue ingrowth into her mitral prosthesis (Fig. I). The diagnosis of paravalvular regurgitation was confirmed by left ventriculography, surgical exploration, or both, in all but one patient. This one exception (Case $r$ ) developed a new apical holosystolic murmur after mitral valve replacement. He subsequently underwent right heart catheterization at which time prominent $\mathrm{V}$ waves were shown in his pulmonary capillary wedge tracing. The intravalvular regurgitation was recognized by the presence of prominent $V$ waves in

FIG. I The ring of tissue ingrowth into the mitral Starr-Edwards prosthesis conspicuously narrowing the inflow orifice of this prosthetic valve is shown above. The orientation is such that the left atrial portion of the prosthesis is at the top.

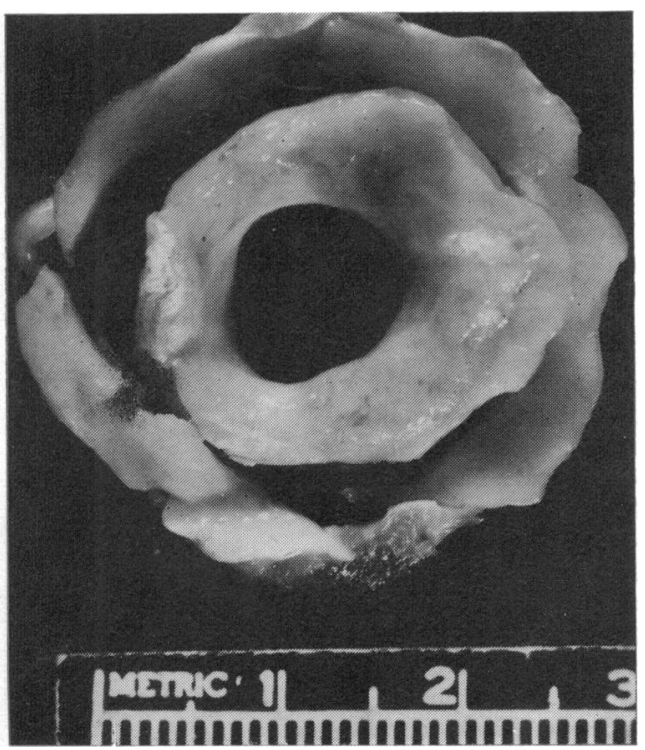

the pulmonary capillary wedge tracing of Case 10, which appeared with exercise.

Paravalvular regurgitation around mitral prostheses was detected in these patients from 24 hours to 6 years after mitral valve replacement. The aetiology of the mitral valve disease originally was rheumatic heart disease in 10 of the II patients (Table I). In the eleventh, ruptured chordae tendineae were responsible for the mitral regurgitation. Nine of these patients had heavily calcified mitral annuli and/or leaflets, while in 2 no calcium was seen on fluoroscopy and none discovered at the time of operation. In all of those with paravalvular regurgitation the leak occurred through a circumferential rent in the atrium adjacent to the sewing ring of the prosthesis. One patient (Case 3) had a left atrial clot as well as a small mitral regurgitant leak.

Group II Fifteen patients with clinically normal mitral prosthetic function (12 women and $3 \mathrm{men}$ ) were studied. Fourteen had Starr-Edwards mitral prostheses and one a Beall valve. Five also had Starr-Edwards aortic prostheses (Table 2). None of these patients had haemodynamically significant additional valvular heart disease. All were on digitalis preparations and 4 were taking diuretics. None of them had systemic hypertension. Six were in atrial fibrillation and 9 in sinus rhythm at the time of study. Mean heart rate for this group was 84 beats a minute. Confirmation of normal prosthetic function was subsequently provided in 2 of these patients by left ventricular angiography. A third patient died; necropsy revealed no evidence of paravalvular regurgitation.

Group III The third group consisted of 4 patients (all men) without clinical evidence of paravalvular regurgitation but with clinical evidence of severe left ventricular failure after mitral valve replacement (mean 3 years) (Table 3). All of these patients had large, dilated, poorly contracting left ventricles suggesting intrinsic myocardial disease. Each had follow-up cardiac catheterization with left ventricular angiography which showed normal 
mitral prosthetic function. All 4 were receiving digitalis preparations, low sodium diets, and diuretics. None of these patients had systemic hypertension and none of them had aortic prostheses.

Non-invasive techniques including phonocardiograms, apex cardiograms, carotid arterial pressure tracings, and electrocardiograms were obtained in each. Records were made by a Sanborn 560 (Hewlett-Packard) phonocardiograph machine which includes 350-3200A preamplifiers for apex and electrocardiography and $350-1700 \mathrm{C}$ preamplifiers for phonocardiography. The studies were obtained in a sound-proof room at a paper speed of a $100 \mathrm{~mm} / \mathrm{sec}$ with $0.04 \mathrm{sec}$ time lines. Heart sounds and murmurs were recorded with Leatham suction microphones at the apex, in the fifth intercostal space along the left sternal border, and in the second left intercostal space at frequencies ranging from 400 to 25 c.p.s. At least 8 consecutive cycles were analysed and averaged to obtain a mean value for the intervals under study. In the presence of atrial fibrillation at least 12 consecutive cycles were analysed and averaged together to obtain a mean value for the interval of interest. The accuracy of measurement was considered to be between 5 and 10 msec. The following indices were derived from the above measurements.

I Left ventricular ejection time (LVET) = interval between the onset of the carotid upstroke and the incisura. LVET was corrected for heart rate by the method of Weissler, Harris, and Schoenfeld (I969).

2 A2-OCMV = interval between aortic closure and the opening click of the mitral prosthesis.

3 Pre-ejection period (PEP) = electromechanical systole (Q-S2 interval)-LVET. PEP was also corrected for heart rate (Weissler et al., 1969).

4 Q-SI interval=interval between the onset of the $Q$ wave and the high frequency closing click of the mitral prosthesis.

Differences between actual and predicted LVET and PEP ( $\triangle$ LVET and $\triangle \mathrm{PEP}$ ) and A2OCMV intervals were compared statistically. ${ }^{1}$ Statistical comparisons were made between Groups I and II. Group III with only 4 patients was not included in the statistical comparisons. Case ro (Table I) was excluded from the statistical comparisons of A2-OCMV and LVET intervals because of interference with ball movement resulting from tissue ingrowth.

The amplitude of both the opening and closing clicks of the mitral prostheses was recorded and compared at the left sternal border and at the apex.

In each case the presence and severity of the mitral paravalvular regurgitation were evaluated on the basis of retrograde left ventricular angiocardiograms. A trace of regurgitation occurring in early systole, with 'smoke ring' configuration,

1 The authors are indebted to Dr. John Gilbert and Mrs. Jacqueline Lustgarten for statistical assistance.
TABLE 2 Phonocardiographic features of Group II patients

\begin{tabular}{|c|c|c|c|c|c|}
\hline Case No. & $\begin{array}{l}\text { Age and } \\
\text { sex }\end{array}$ & $\begin{array}{l}\triangle L V E T \\
\text { (msec) }\end{array}$ & $\begin{array}{l}A 2-O C M V \\
(\mathrm{sec})\end{array}$ & $O C M V$ & Murmur \\
\hline 12 & $42 F$ & $32 \cdot 4$ & 0.12 & Normal & Nearly holosystolic \\
\hline I3 & $44 M$ & $28 \cdot 5$ & 0.08 & Normal & Prosthetic aortic valve \\
\hline I4 & $5 \mathrm{I} \mathrm{F}$ & 66 & 0.12 & Normal & Soft holosystolic \\
\hline I5 & $48 M$ & 33 & 0.10 & Normal & Soft systolic ejection \\
\hline I6 & $40 \mathrm{~F}$ & 72 & 0.12 & Normal & None \\
\hline 17 & $68 \mathrm{~F}$ & 82 & 0.10 & Normal & Soft systolic ejection \\
\hline 18 & $42 \mathrm{~F}$ & 65 & 0.10 & Normal & Systolic ejection \\
\hline $19^{\star}$ & $72 \mathrm{~F}$ & 40 & $0 \cdot 10$ & Normal & Prosthetic aortic valve \\
\hline $20 *$ & $50 \mathrm{~F}$ & I6 & 0.07 & Normal & Prosthetic aortic valve \\
\hline $2 I^{\star}$ & $60 \mathrm{~F}$ & 68 & 0.08 & Normal & Prosthetic aortic valve \\
\hline $22^{\star}$ & $54 \mathrm{~F}$ & 42 & $0 \cdot 1 \mathrm{I}$ & Normal & Prosthetic aortic valve \\
\hline 23 & $48 \mathrm{~F}$ & $47 \cdot 2$ & 0.09 & Normal & Systolic ejection \\
\hline 24 & $52 \mathrm{~F}$ & Io & 0.10 & Normal & Systolic ejection \\
\hline 25 & $48 \mathrm{~F}$ & 78 & 0.10 & Normal & Systolic ejection \\
\hline 26 & $6 \mathrm{IM}$ & 0 & O.II & Normal & Systolic ejection \\
\hline
\end{tabular}

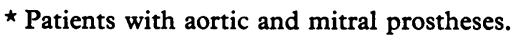

was commonly seen in patients with ball and cage prostheses and was considered to be normal for these patients (Rockoff et al., 1966). Any regurgitation occurring around the prosthetic ring was considered to be abnormal. This was graded as mild, moderate, or severe in amount, based upon the degree of opacification of the left atrium with appropriate consideration of the size of this chamber as it affected dilution of the contrast medium (Steiner et al., 1963).

\section{Results}

Interval from aortic closure to opening click of mitral prosthesis (A2-OCMV) A2-OCMV intervals were significantly reduced in the patients with MPR(Group I) (Fig. 2). This was also true when patients with MPR with just Starr-Edwards prostheses were compared with those with just Starr-Edwards prostheses in Group II (Fig. 3). The shorter A2-OCMV intervals tended to occur among patients in Group I with the more severe degrees of paravalvular regurgitation though one patient (Case 5) with severe paravalvular

TABLE 3 Phonocardiographic features of Group III patients

\begin{tabular}{|c|c|c|c|c|c|}
\hline $\begin{array}{l}\text { Case } \\
\text { No. }\end{array}$ & $\begin{array}{l}\text { Age and } \\
\text { sex }\end{array}$ & $\begin{array}{l}\triangle L V E T \\
(\mathrm{msec})\end{array}$ & $\begin{array}{l}A 2-O C M V \\
(\mathrm{sec})\end{array}$ & $O C M V$ & Murmur \\
\hline 27 & $76 \mathrm{M}$ & $58 \cdot 7$ & $0 \cdot 10$ & Diminished & $\begin{array}{l}\text { Soft systolic ejection } \\
\text { murmur }\end{array}$ \\
\hline 28 & $58 \mathrm{M}$ & 57 & $0 \cdot 10$ & Normal & $\begin{array}{l}\text { Soft systolic ejection } \\
\text { murmur }\end{array}$ \\
\hline 29 & $50 \mathrm{M}$ & 65.5 & 0.11 & Normal & $\begin{array}{l}\text { Soft systolic ejection } \\
\text { murmur }\end{array}$ \\
\hline 30 & $85 \mathrm{M}$ & 43 & 0.085 & Normal & $\begin{array}{l}\text { Soft systolic ejection } \\
\text { murmur }\end{array}$ \\
\hline
\end{tabular}

$\triangle \mathrm{LVET}, \Delta$ left ventricular ejection time; A2-OCMV, interval from aortic closure to mitral valve opening; OCMV, opening click of mitral valve. 


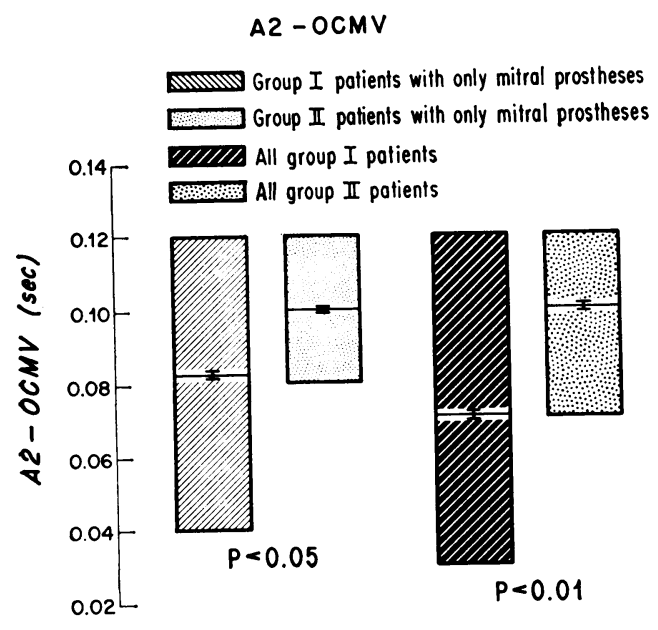

FIG. 2 A comparison of A2-OCMV intervals between Group I and Group II patients is shown. The comparisons are between patients with only a mitral prosthesis in Groups I and II and all of the patients in both groups. The horizontal lines represent mean values, the brackets standard errors, and the bars the ranges.

regurgitation had a normal A2-OCMV (Table 4). There was considerable overlap in A2OCMV intervals between patients with only mild or moderate MPR and the patients in Group II (Tables 2 and 4). There was also overlap with the Group II patients in 3 additional patients in Group I in whom it was not possible to quantify the amount of paravalvular regurgitation. The patient with tissue

\section{FIG. 3 A2-OCMV intervals for Group I} and Group II patients with Starr-Edwards prostheses. The symbols are the same as those described for Fig. 2.

A2-OCMV (Starr-Edwards Prostheses)

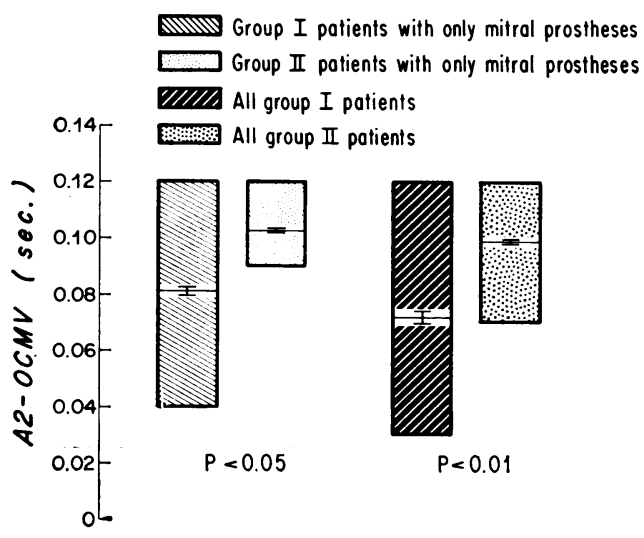

ingrowth into her mitral prosthesis (Case 10) had a slightly prolonged A2-OCMV interval of $0.144 \mathrm{sec}$ probably due to delayed mitral valve opening.

In Group II patients A2-OCMV intervals for all patients ranged from 0.07 to $0.12 \mathrm{sec}$, with a mean value of 0.10 sec (Table 2). A similar range in A2-OCMV intervals was found in patients in Group III (Table 3).

There was no consistent relation between heart rate and A2-OCMV intervals in the patients studied. A2-OCMV intervals were shorter in both the Group I and Group II patients who had both mitral and aortic prostheses as compared to when only a mitral prosthesis was present (Table 5). This shortening was of statistical significance in the Group II patients.

Left ventricular ejection time (LVET) There was significant shortening of the LVET when all the patients with paravalvular regurgitation (Group I) were compared with all the patients with normal prosthetic mitral valve function (Group II) (Fig. 4) (Tables 2 and 4). A separate comparison of LVET between Group I and Group II patients with just Starr-Edwards prostheses also showed a shortened LVET in the Group I patients (mean $\triangle$ LVET 63.31 msec (6.49 SEM) in Group I and $49 \cdot 16 \mathrm{msec}(6.42$ SEM) in Group II), but the difference was just outside the range of statistical significance. All 4 of the Group III patients had a shortened LVET, and in one the degree of shortening was comparable to the mean reduction seen in Group I patients (Table 3 ).

Opening click mitral valve/closing click mitral valve (OCMV/CCMV ratio) In the 15 patients in Group II with StarrEdwards prostheses the ratio of amplitude of opening to closing click of the mitral prosthesis was 35 per cent or greater along the left sternal border and at the apex (Fig. 5). Four patients with paravalvular and the patient with intravalvular regurgitation had OCMV intensities less than 35 per cent of that noted for the closing click. Fig. 6 is a representative example of the reduced opening click in these patients. One of these patients with paravalvular regurgitation had a Beall valve and a reduced opening click. The remaining 3 patients had Starr-Edwards prostheses and opening clicks of reduced amplitude recorded along the left sternal border. However, in these 4 patients the opening clicks at the apex appeared to be of normal intensity with high frequency recordings $(400 \mathrm{cps})$. Two of these 4 patients (Cases 4 and 5) had severe para- 
TABLE 4 Phonocardiographic and angiographic features of Group I patients

\begin{tabular}{|c|c|c|c|c|c|}
\hline Case No. & $\begin{array}{l}\triangle L V E T \\
\text { (msec) }\end{array}$ & $\begin{array}{l}A 2-O C M V \\
(\mathrm{sec})\end{array}$ & Murmur & $O C M V$ & Severity of leak $\ddagger$ \\
\hline $\mathbf{I}$ & 74 & 0.12 & Prominent holosystolic (apex) & Diminished & Unable to determine \\
\hline 2 & 82 & 0.08 & Soft holosystolic (LSB) & Normal & Moderate MR \\
\hline 3 & 44.4 & 0.098 & Prominent holosystolic & Normal & Mild MR \\
\hline 4 & 62 & 0.04 & None & Diminished & Severe MR \\
\hline 5 & 64.4 & $0 \cdot 10$ & Soft systolic ejection (apex) & Diminished & Severe MR \\
\hline 6 & 85.5 & 0.07 & $\begin{array}{l}\text { Short, soft systolic ejection } \\
\text { (LSB, apex) }\end{array}$ & Normal & Severe MR \\
\hline $7^{\star}$ & $75 \cdot 4$ & 0.08 & $\begin{array}{l}\text { Aortic prosthetic murmur } \\
\text { only }\end{array}$ & Diminished & Unable to accurately estimate \\
\hline $8 *$ & $42 \cdot 3$ & 0.03 & $\begin{array}{l}\text { Soft systolic ejection (LSB, } \\
\text { apex) }\end{array}$ & Normal & Severe MR \\
\hline 9 & 89 & 0.08 & $\begin{array}{l}\text { Prominent holosystolic (LSB, } \\
\text { apex) }\end{array}$ & Normal & Unable to accurately estimate \\
\hline rot & $62 \cdot 8$ & $0 \cdot 144$ & Prominent holosystolic (apex) & Diminished & No MR at rest (see Results) \\
\hline$I I^{\star}$ & 37 & 0.06 & $\begin{array}{l}\text { Prosthetic aortic valve } \\
\text { murmur extending } \\
\text { throughout systole }\end{array}$ & Normal & Moderate MR \\
\hline
\end{tabular}

* Patient had both aortic and mitral prostheses.

$\dagger$ Mechanical interference with ball seating due to tissue ingrowth.

¥ Severity of leak as demonstrated by LV angiogram or at surgery where LV angiogram was not done or did not for technical reasons permit an assessment of the severity of the paravalvular leak.

LVET, left ventricular ejection time.

valvular regurgitation (Table 4 ) while in the semaining 2 (Cases $I$ and 7 ) the severity of the leak is unknown. Both of the patients with severe paravalvular regurgitation had increased amplitude of their opening clicks in their postoperative studies, as did Case 7. Case I did not undergo surgical repair of the regurgitation.

× One of the patients in Group III (Case 27) also had a reduced opening click of his StarrEdwards mitral prosthesis (Fig. 7). His opening click was reduced in recordings taken from both the left sternal border and at the apex.

Third heart sounds Typical third heart sounds were not recorded in any of these patients (total of 30 patients) with mitral prostheses regardless of whether paravalvular regurgitation or severe left ventricular failure , were present. Some of the patients in all 3

TABLE 5 Shortened A2-OCMV intervals in patients with both aortic and mitral prostheses

\begin{tabular}{|c|c|c|}
\hline \multirow[t]{2}{*}{ apatients } & \multicolumn{2}{|c|}{$A 2-O C M V(\text { mean })^{*}$} \\
\hline & Mitral prostheses & $\begin{array}{l}\text { Mitral and } \\
\text { aortic prostheses }\end{array}$ \\
\hline Group I $†$ & $\begin{array}{l}0.084 \mathrm{sec}(0.009 \\
\text { SEM) }\end{array}$ & $\begin{array}{l}0.056 \mathrm{sec}(0.01 \\
\text { SEM) }\end{array}$ \\
\hline Group II & $\begin{array}{l}0.106 \mathrm{sec}(0.003 \\
\text { SEM) }\end{array}$ & $\begin{array}{l}0.088 \mathrm{sec}(0.007 \\
\text { SEM) }\end{array}$ \\
\hline
\end{tabular}

* The degree of reduction in A2-OCMV intervals is of statistical significance in the Group II patients $(\mathrm{P}<0.025)$.

' † Patients with MPR.

$¥$ Patients with normal mitral prosthetic function.
FIG. $4 A$ comparison of $\Delta$ left ventricular ejection times between Group I and II patients with only a mitral prosthesis and also between all Group I and Group II patients. The horizontal bars represent standard errors of the mean and the symbols the mean value.

\section{$\triangle$ LEFT VENTRICULAR EJECTION TIME}

O Group I patients with only mitral prostheses

Group II patients with only mitral prostheses

All group I potients
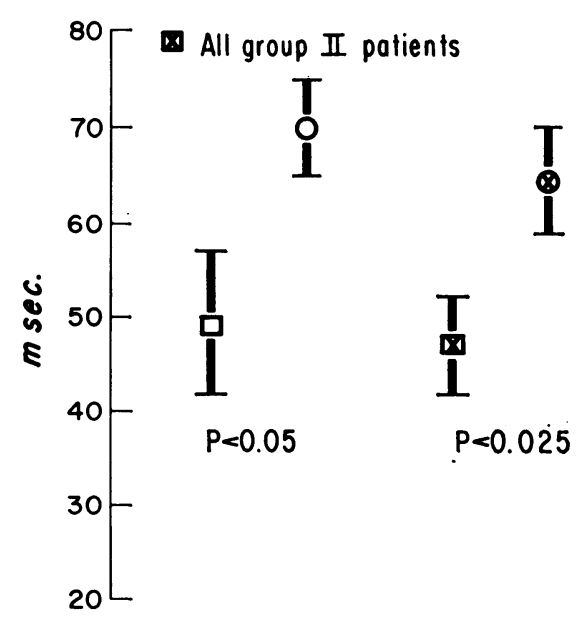


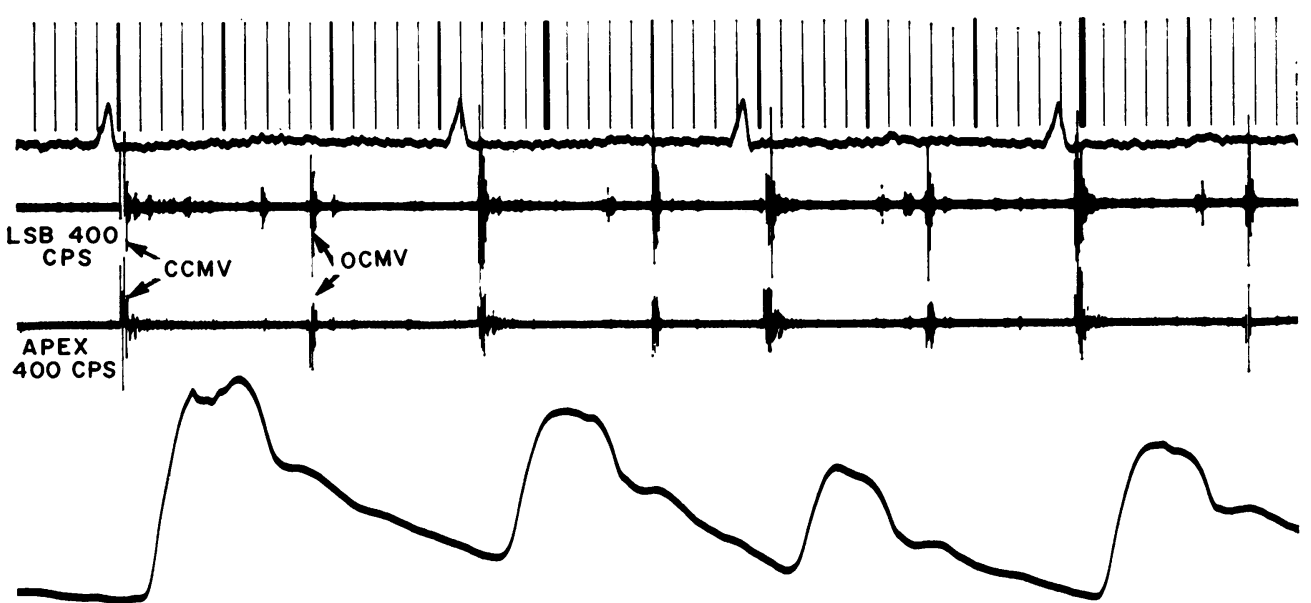

FIG. 5 The opening and closing clicks in a normally functioning mitral prosthesis are shown.

groups had 'prosthetic S3's' (Hultgren and Hubis, 1965), but there did not appear to be any difference between patients with and without mitral paravalvular regurgitation in this regard.

Murmurs The murmur of mitral paravalvular regurgitation tended to be best heard and recorded at the apex, was usually holosystolic in timing, and frequently radiated into the back (Table 4). With severe paravalvular regurgitation the murmurs were much softer and shorter and in one patient (Case 6) there was neither an audible nor a recordable murmur (Fig. 8).

Apical systolic murmurs were common among Group II and III patients varying from ejection to being holosystolic in timing, but all were relatively soft (Tables 2 and 3).

Q-Sr and PEP intervals There were no significant differences between Group I and II patients as regards Q-SI intervals $(0.06 \mathrm{I}$ sec $(0.002$ SEM) versus $0.060 \mathrm{sec}(0.004$ SEM)) or $\triangle$ PEP's (9 msec (7 msec SEM) versus $\mathrm{I}_{3} \mathrm{msec}(8 \mathrm{msec} \mathrm{SEM})$ ).

\section{Discussion}

The phonocardiographic clues to the presence of mitral paravalvular or intravalvular regurgitation in this series were a shortened aortic

FIG. 6 Panel on the upper left shows the reduced opening click of Case Io with tissue ingrowth into the mitral prosthesis. The panels on the upper right and at the bottom of the Fig. show a normal opening click after mitral valve replacement.
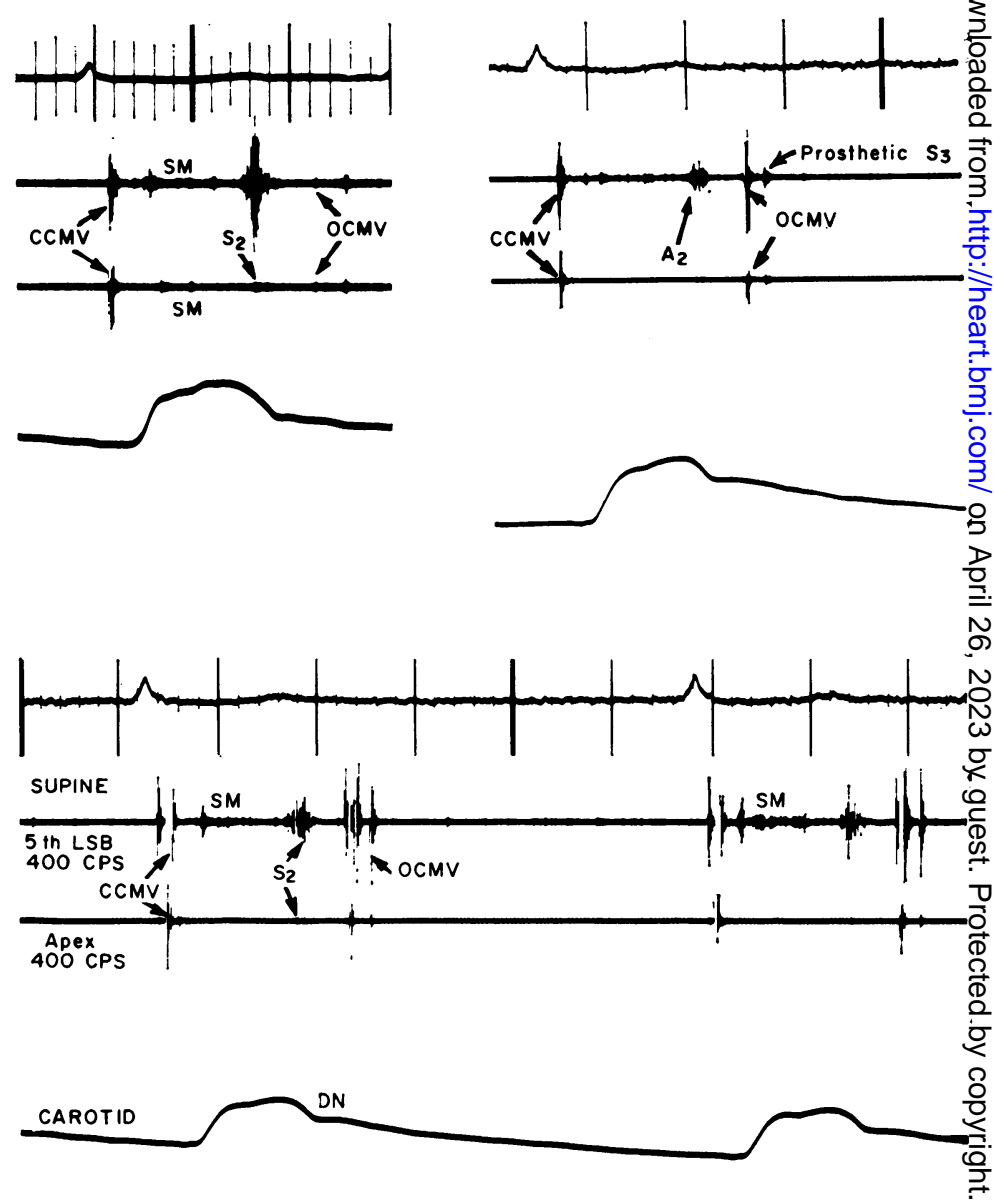
closure to mitral opening click interval (A2OCMV) and a reduced left ventricular ejection time (LVET). The A2-OCMV interval was the single most useful non-invasive sign in this study in separating patients with severe mitral paravalvular regurgitation from those without mitral paravalvular regurgitation. For patients with milder degrees, however, the A2-OCMV may not be reduced. The reduction in A2-OCMV, when present, presumably reflects increased left atrial pressure, and it therefore is to be expected that the shortest A2-OCMV intervals would be found in patients with the most severe form. In measuring the A2-OCMV interval it should be noted that patients with both aortic and mitral prostheses have shortened A2-OCMV intervals even in the absence of regurgitation. This has also been reported by others (Hultgren and Hubis, 1965). The reduced A2-OCMV interval is probably the result of delayed aortic valve closure in patients with aortic prostheses as compared to those patients without them. Prolonged A2-OCMV intervals may be present in patients with tissue ingrowth into the mitral prosthesis interfering with ball movement of a Starr-Edwards prosthesis as was seen in Case Io in Group I. This also seems to occur in patients with a left atrial thrombus that interferes with mitral prosthetic function (Craige, Hutchin, and Sutton, 1970).

The finding of a reduced LVET was also of some value in suspecting the presence of mitral paravalvular or intravalvular regurgitation. In this series, Group I patients had a shorter LVET than those patients with normally functioning mitral prostheses though considerable overlap between Group I and Group II and III patients was present. The finding of a reduced LVET in patients with paravalvular or intravalvular regurgitation can be attributed to any combination of the following.

I Left ventricular failure (Weissler, Harris, and Schoenfeld, 1968).

2 Digitalis preparations (Weissler et al., 1964).

3 The systolic unloading of the left ventricle into the left atrium provided by the paravalvular or intravalvular regurgitation.

The murmur of a mild to moderate paravalvular leak around a mitral prosthesis is a holosystolic apical one of varying intensity. From the data obtained from these patients it appears that with severe mitral paravalvular regurgitation the murmur becomes both shorter and and softer or may entirely disappear
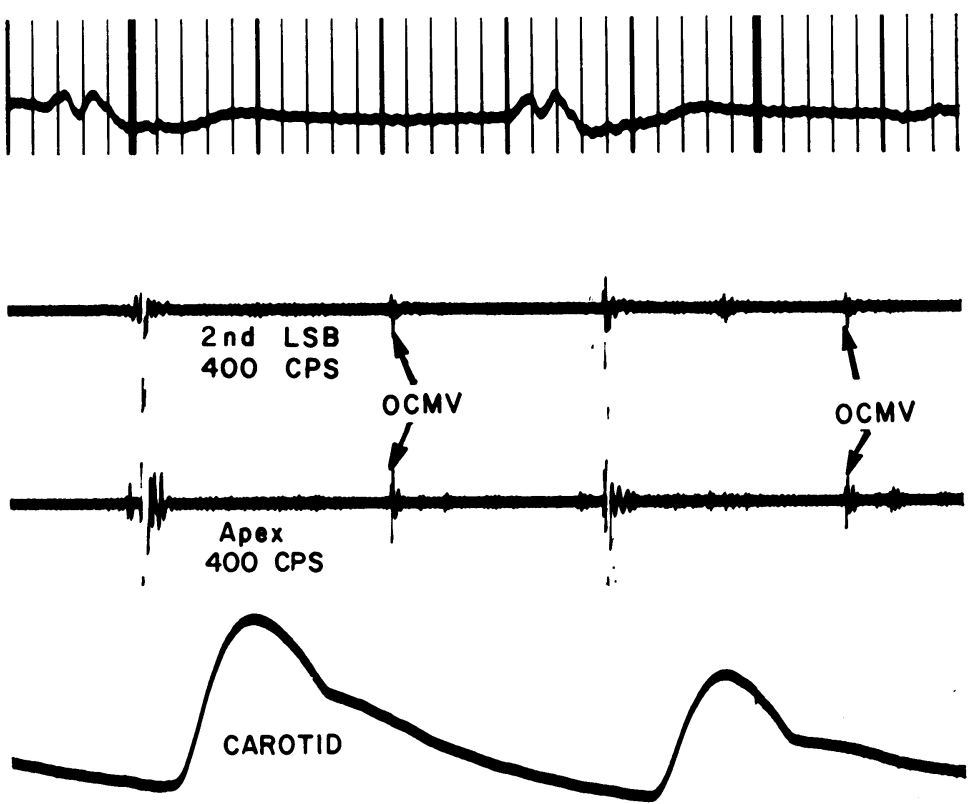

FIG. 7 The reduced opening click in Case 27 in Group $I I I$ is shown.

(Table 4). Other authors have noted that murmurs may be absent in the presence of paravalvular regurgitation but the correlation of absent or unimpressive murmurs with severe regurgitation has not been previously emphasized. The mechanism involved in the reduction and, at times, disappearance of the apical systolic murmur is not known but presumably reflects a regurgitant jet of low velocity due to left ventricular failure, a large regurgitant orifice, or a combination of the two. As previously noted, systolic murmurs were frequently present in the patients in this series with normally functioning mitral prostheses, but these tended to be soft systolic ejection murmurs rather than prominent apical holosystolic ones.

Reduced opening clicks deserve special mention. While it is not presently possible to be certain that an OCMV/CCMV of less than 35 per cent will mean abnormal mitral valve function or severe left ventricular failure, this ratio did help to identify reduced opening clicks in 5 patients in this series with either paravalvular regurgitation or tissue ingrowth and intravalvular regurgitation. It is of interest that 4 patients with paravalvular regurgitation had reduced opening clicks along the upper left sternal border but normal intensity to the opening click at the apex. Perhaps the presence and radiation of the reduced opening click associated with paravalvular regurgitation is explained by the tilting of the prosthe- 

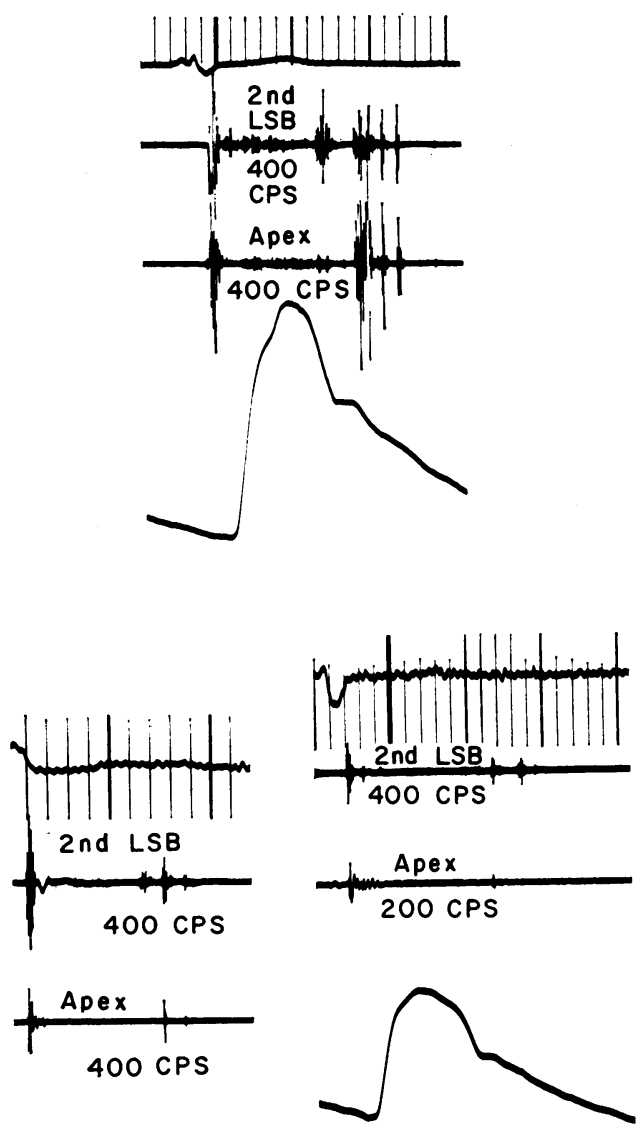

FIG. 8 The top panel is from Case 3 with a mild paravalvular leak. The bottom two panels are from two patients (Cases 4 and 5) with severe mitral paravalvular regurgitation but barely detectable murmurs.

sis previously postulated by Leachman and Cokkinos (1969). One additional patient (Case 27 in Group III) had a reduced opening click but no regurgitation: he had severe left ventricular failure and at necropsy no thrombus or tissue ingrowth interference was found; the ball did not appear to have degenerated. It may be that sluggish movement of the ball from seat to cage does occur in some patients with severe left ventricular failure. Thus, a reduced opening click in patients with Starr-Edwards prostheses may be an indication of paravalvular regurgitation, mechanical interference with the ball movement, or left ventricular failure.

Despite the presence of varying degrees of mitral regurgitation (mild to severe), ventricular filling sounds ( $\mathrm{S}_{3}$ 's) were not recorded in any of these patients. This has also been reported by other investigators (Ikram, Makey, and Bliss, 1969). The absence of the normal mitral valve apparatus, and especially its supporting structures, is the most likely explanation for the inability to record filling sounds in these patients.

In summary, the presence of a reduced A2-OCMV, a conspicuously reduced LVET, or diminished intensity of the opening click of the mitral prosthesis suggest the possibility of mitral paravalvular regurgitation. If the paravalvular regurgitation is mild, an apical systolic murmur should be present but with severe paravalvular regurgitation the apical murmur may become unimpressive or totally disappear. A conspicuously reduced A2OCMV occurs with severe mitral paravalvular regurgitation. Regurgitation of mild to moderate severity may be present, however, without recognizable changes in the non-invasive parameters measured in this study.

The authors would like to express their appreciation to Drs. Gordon Myers, Edgar Haber, and Peter Yurchak for their review and helpful criticism of the manuscript.

\section{References}

Craige, E., Hutchin, P., and Sutton, R. (1970). Impaired function of cloth-covered Starr-Edwards mitral valve prosthesis. Detection by phonocardiography. Circulation, 4I, I4I.

Hultgren, H. N., and Hubis, H. (1965). A phonocardiographic study of patients with the Starr-Edwards mitral valve prosthesis. American Heart fournal, 69, 306.

Ikram, H., Makey, A. R., and Bliss, B. P. (1969). Genesis of diastolic sounds in mitral incompetence. British Heart fournal, 31, 762.

Leachman, R. D., and Cokkinos, D. V. P. (1969). Absence of opening click in dehiscence of mitralvalve prosthesis. New England fournal of Medicine, 28I, 46 I.

Rockoff, S. D., Ross, J., Jr., Oldham, N. N., Jr., Mason, D. T., Morrow, A. G., and Braunwald, E. (1966). Ventriculo-atrial regurgitation following prosthetic replacement of the mitral valve. Angiocardiographic and hemodynamic findings. American fournal of Cardiology, 17, 817.

Steiner, R. E., Jacobson, G., Dinsmore, R., and Parizel, G. (1963). Mitral regurgitation. Clinical Radiology, 14, II3.

Weissler, A. M., Gamel, W. G., Grode, H. E., Cohen, S., and Schoenfeld, C. D. (I964). The effect of digitalis on ventricular ejection in normal human subjects. Circulation, 29, 721 .

Weissler, A. M., Harris, W. S., and Schoenfeld, C. D. (1968). Systolic time intervals in heart failure in man. Circulation, 37, 149.

Weissler, A. M., Harris, W. S., and Schoenfeld, C. D. (I969). Bedside techniques for the evaluation of ventricular function in man. American fournal of Cardiology, 23, 577.

Requests for reprints to Dr. James T. Willerson, Cardopulmonary-D-7 10, University of Texas Southwestern, Medical School at Dallas, 5323 Harry Hines Boulevard, Dallas, Texas 75235 . 